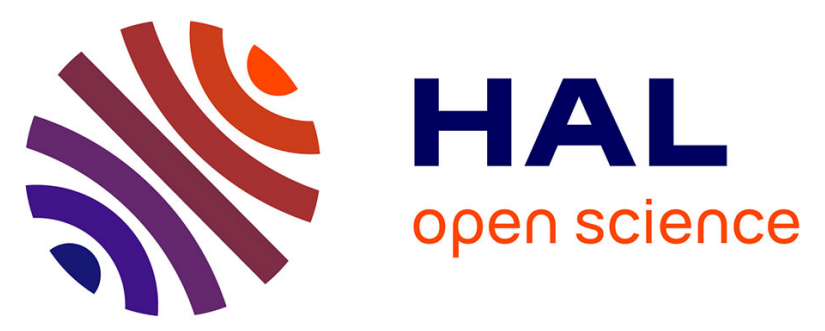

\title{
Review of W. Heinrich and R. Abart (eds.) (2017): Mineral reaction kinetics: microstructures, textures, chemical and isotope signatures. EMU Notes in Mineralogy, 16
}

Jérôme Sterpenich

\section{To cite this version:}

Jérôme Sterpenich. Review of W. Heinrich and R. Abart (eds.) (2017): Mineral reaction kinetics: microstructures, textures, chemical and isotope signatures. EMU Notes in Mineralogy, 16. European Journal of Mineralogy, 2019, 31 (1), pp.193-194. 10.1127/ejm/2019/0031-2835 . hal-02968202

\section{HAL Id: hal-02968202 \\ https://hal.science/hal-02968202}

Submitted on 15 Oct 2020

HAL is a multi-disciplinary open access archive for the deposit and dissemination of scientific research documents, whether they are published or not. The documents may come from teaching and research institutions in France or abroad, or from public or private research centers.
L'archive ouverte pluridisciplinaire HAL, est destinée au dépôt et à la diffusion de documents scientifiques de niveau recherche, publiés ou non, émanant des établissements d'enseignement et de recherche français ou étrangers, des laboratoires publics ou privés. 


\section{Review of}

\section{W. Heinrich and R. Abart (eds.) (2017): Mineral reaction kinetics: microstructures, textures, chemical and isotope signatures. EMU Notes in Mineralogy, 16, European Mineralogical Union and Mineralogical Society of Great Britain and Ireland: London. ISBN 978-0903056-63-2, XV, 651 p., £ 55 (institutions), £ 40 (individuals)}

JÉRÔME STERPENICH, Université de Lorraine, CNRS, CREGU, GéoRessources laboratory, B.P. 70239, 54506 Vandoeuvre-lès-Nancy, France - jerome.sterpenich@univ-lorraine.fr

\section{Preamble}

As a geochemist, specialist in fluid-rock interactions, I have undertaken the task of reviewing this book from the perspective of a nonspecialist, with the exception of chapters dealing with aqueous solution and mineral or glass alteration which is within my speciality. My review should be considered the opinion of a general scientist who wants to learn more about mineral transformations from a kinetic and thermodynamic point of view. The reader should be aware that this volume rather deals with processes at the nanometre scale explaining mechanical, textural and physical properties of minerals and rocks, than mineral weathering.

\section{Introduction}

The book begins with an introduction by Abart and Heinrich, who explain the global philosophy of the volume, dealing with experimentation and analytical techniques to better understand and quantify the kinetics of mineral reactions. The book, composed of 17 chapters, treats three main aspects: 1) the state-of-the-art experimental and analytical techniques recently developed; 2) the processes involved in mineral reactions, mainly diffusion processes, nucleation and growth, with an emphasis on theoretical basis; 3) application of these theories and techniques to geomaterial research and geology, without forgetting isotopic investigation.

\section{Experimental approach}

Milke et al. present a paper on experiments devoted to diffusioncontrolled mineral reactions, starting with conventional techniques applied however at high pressure and temperature, to then move progressively towards elaborate devices, like time-resolved X-ray diffraction and in situ monitoring of mineral reactions. The emphasis is on very high pressure (up to $50 \mathrm{GPa}$ in multi-anvil press) and high temperature (up to $2000{ }^{\circ} \mathrm{C}$ ) conditions together with the important role of water in reaction kinetics. The authors also give a good overview of the new analytical techniques applied to variable experimental setups (X-ray tomography, synchrotron radiation, FIB TEM, IFTR, $\mathrm{X}$-ray diffraction...). Note that the studied systems are mainly applied to metamorphic rocks.

The second paper by Zaefferer \& Habler treats scanning electron microscopy (SEM) and focuses more precisely on electron backscattered diffraction (EBSD), which allows the quantification of microstructures in crystallized solids at high resolution $(50-200 \mu \mathrm{m})$. The authors do not neglect the "classical" analyses methods coupled with SEM such as EDS, WDS, cathodoluminescence, Auger spectroscopy.... Young and perhaps less young researchers can find here a useful brief although comprehensive description of the physical theory of these different techniques of analysis or imagery. Coming back to EBSD, the paper devotes the second (and the main) chapter to this promising technique that, combined with EDX, provides extensive information on the crystallographic properties of the samples (orientation, defects, microstructures...). This technique is illustrated through two examples, one from metallurgy, namely a Ni-based super alloy coated to obtain specific thermal properties, the second from geosciences, with the study of the quartz/forsterite reactivity after compaction at high pressure and high temperature. In both cases, the study focused on new crystallizations at the interfaces induced by the process. It allows the precise determination of crystallographic properties of newly formed micro-crystals and gives information on the mechanisms of phases transformations and crystallization. The reader will also find all the concepts used to interpret EBSD data.

A powerful complementary technique to SEM is transmission electron microscopy (TEM) which is the subject of chapter four, written by R. Wirth. This chapter deals mainly with TEM applications in geosciences. TEM is a powerful tool to characterize both the crystallography and the chemical composition of micro to nano-phases. The paper is divided in three chapters where the theory explains practical cases. The reader will be familiarized with EDX analysis and especially a sensitization to error calculation and detection limits, which is too often forgotten in many scientific publications. The application of the powerful but delicate electron energy-loss spectroscopy (EELS) is detailed, especially the "classical" determination of metals valence (e.g. $\mathrm{Fe}^{3+} / \mathrm{Fe}^{2+}$ ), but also the possibility to distinguish polymorphs without diffraction pattern. A complete chapter dedicated to electron diffraction and the consequent crystallographic application at the nanometric scale is followed by the last one dealing with the determination of microstructures of minerals and grains by TEM.

The next chapter by Deloule \& Valle provides a basis for in situ analysis of trace elements and isotopes, thanks to secondary ion mass spectrometry (SIMS). The big advantage of such technique is the possibility to analyze, with a very low detection limit, light elements and isotopes on thin or polished sections, with a good spatial resolution (up to $50 \mathrm{~nm}$ ). It also allows the recording of depth profiles with extremely high in-depth resolution as well as the ability to carry out isotope or elemental 3D mapping. After a precise description of the technical and analytical aspects and with emphasis on sensitivity, detection limits and precision, two examples are discussed in detail, giving a good overview of the advantages of the technique. The first example is based on the alteration of silicate glasses (nuclear waste), while the 
second deals with lithium as a tracer of magmatic processes, both from its variation of concentration and isotopic composition.

A short chapter by Schroer dedicated to synchrotron techniques concludes the part dedicated to the analytical techniques.

\section{Theoretical aspects}

The section on theoretical aspects begins with a paper from Svoboda et al. with mathematical aspects, sometimes arduous for non-specialists, of the thermodynamic modelling of irreversible processes, explained here by the Thermodynamic Extremal Principle (TEP). The theory is then applied to grain growth and precipitate coarsening as well as solid state precipitation. The paper shows that precipitation kinetics can be predicted by numerical simulation in multi-component multi-phase multi-particle systems.

Atomic-scale modelling is developed in the detailed paper of Jahn $\&$ Sun. The authors explain with a pedagogical approach how it is possible to model properties of materials from molecular dynamic simulations or static energy calculations. The emphasis is put on the modelling of crystal defects, self-diffusion and deformation in crystals. It is elegantly completed by Petrishcheva \& Abart with the mathematics of diffusion, in which the reader gets familiar with self-similar solutions or non-linear diffusion. Aid is also proposed for those who want to solve inverse problems: how to quantify diffusivity from experimental data? Because interfaces determine many physical or chemical properties of complex systems, Petrishcheva \& Abart proceed with a chapter dedicated to the phenomenological treatment of interfaces. The progression of reasoning from capillary forces to interface movements allows the reader to follow the concepts used to describe phenomena such as coarsening, grain growth or organization of grain boundaries. Because nucleation must precede growth, the paper on nucleation by Gaidies is of great interest to understand phase transformations. Mainly based on classical nucleation theory, it also deals with non-classical gradient energy approaches to model the influence of chemical heterogeneities on nucleation kinetics, or with the phase field method which provides new insight to better understand texture of rocks. The link is obvious with the next chapter, by Mollo \& Hammer, where crystallization from magmas is treated. The reader will apply his newly acquired knowledge on nucleation and growth, interfaces or diffusion processes to magmas submitted to heat dissipation, decompression and under-cooling, finally leading to crystallization. Minerals-melt partitioning are discussed as well as textural outcomes with applications to volcanological problems.

Being a geochemist, I was impatiently waiting for the article of Ruiz-Agudo et al. dedicated to fluid-mineral interactions! After repeating the general theory of nucleation and growth but from an "aqueous solution" point of view, the authors describe the main mechanisms of dissolution and precipitation, with an emphasis on atomic scale phenomena studied from atomic force microscopy (AFM) or interferometry. In particular, they discuss the new theories on crystal growth (prenucleation clusters, amorphous precursors, mesocrystal formation) and juxtapose them with classical ones such as the Terrace-LedgeKing (TLK) model. Models of mineral and glass dissolutions are also revisited with the help of nanometric tools. This chapter offers a good synthesis summarizing the state of the art of fluid-mineral interactions and their application in geological and technological processes.

Back to dry systems with Gaidies et al., who write about metamorphic reactions. A long chapter of 70 pages, where theory on interfaces and diffusion in solid phases is treated (again?) and applied to three types of metamorphic mineral reactions: porphyroblast growth, formation of coronas and symplectite formation. The role of water, not treated here, is highlighted, however!

Habler \& Griffiths follow, with crystallographic orientation relationships (CORs), or how a crystal sharing common boundary segments with another mineral influences the crystal structure of its neighbour. The authors define the COR terminology and especially the different senses that epitaxy can take. The various mechanisms of COR formation are then discussed, followed by implications for the understanding of petrogenetic processes.

The link between mechanical and chemical aspects is addressed in the article by Ulven \& Malte-Sørenssen, where reaction-induced fracturing (and not "fraturing" as written in the header!) is treated. Volume reduction or volume expansion due to mineral reaction induces stresses that are responsible for fractures, which as a consequence can induce the global reaction rate. The authors treat the different phenomena from atomic to outcrop scale and show how they can be modelled.

The book ends with isotopes, both stable and radiogenic, and how they can help us to quantify the kinetics of petrogenetic processes. Van Orman \& Krawczynski remind us the basis of isotope fractionation and illustrate the utility of isotopic tools for cooling speedometry.

\section{Conclusion}

The book "Mineral reaction kinetics: microstructures, textures, chemical and isotope signatures" deals mainly with high-temperature anhydrous phenomena which can be somewhat deceptive for a geochemist like me. However, if the basics of thermodynamics, kinetics and differential equations are well understood, the various articles provide a good overview of the mechanisms leading to mineral reactions as well as of the analytical tools used to quantify them. Moreover, the discussions present the current knowledge, the state of the art and the main stumbling blocks for a better understanding of mechanisms leading to mineral transformations. 